\title{
New record of poorly known bat Myotis phanluongi (Mammalia, Chiroptera) from Southern Vietnam
}

\section{Sergei V. Kruskop}

\begin{abstract}
New record of the insufficiently studied species Myotis phanluongi made on the southern slope of Da Lat Plateau, Southern Vietnam, is discussing. Identification of the specimens and clear distinction of $M$. phanluongi from related species $M$. siligorensis were confirmed by morphometric analysis. It was shown that this species altitudinal range extends downwards to the elevation of ca. $900 \mathrm{~m}$ above sea level and that foraging of $M$. phanluongi not obviously connected with riverine habitats.
\end{abstract}

KEY WORDS: Myotis, Vietnam, Da Lat Plateau, distribution.

Sergei V. Kruskop [kruskop@zmmu.msu.ru], Zoological Museum, Moscow State University, Bolshaya Nikitskaya 6, 125009 Moscow, Russia.

\section{Новая находка малоизученной летучей мыши Myotis phanluongi (Mammalia, Chiroptera) в Южном Вьетнаме}

\section{С.В. Крускоп}

\begin{abstract}
РЕЗЮМЕ. Обсуждается новая находка малоизученного вида Myotis phanluongi на южном макросклоне Далатского плато в южном Вьетнаме. Определение экземпляров и хорошая обособленность M. phanluongi от родственного вида M. siligorensis подтверждены результатами морфометрического анализа. Показано, что вертикальное распространение вида доходит вниз до высоты около 900 м над ур. моря и что кормовое поведение M. phanluongi не обязательно связано с околоводными местообитаниями.
\end{abstract}

КЛЮЧЕВЫЕ СЛОВА: Myotis, Вьетнам, Далатское плато, распространение.

\section{Introduction}

Within the huge genus Myotis the "siligorensis" species group is one of the least studied. Though in the last years certain taxonomic studies of this group were conducted (Borisenko et al., 2009; Tiunov et al., 2012), there still many unsolved questions even in the field of taxonomy. Since members of this group with only few exceptions are relatively rare and demonstrate sporadic distribution, the knowledge about their natural history is quite poor.

Described only few years ago (Borisenko et al., 2009), Myotis phanluongi was known from only two places in Southern Vietnam: terra typica on Hon Ba Mountain in Khanh Hoa Province and Danim River Valley on Da Lat Plateau between Bi Doup and Hon Giao mountains, Lam Dong Province (Abramov et al., 2010; Kruskop, 2013). In both sites this species was recorded at elevations of 1300-1500 m above sea level and observed foraging over mountainous brooks and small rivers (Kruskop, 2013). The other closely related taxon occurring in Vietnam is M. siligorensis alticraniatus, which relations to $M$. siligorensis from India, China and Thailand require revision. This form is widespread in Vietnam, inhabiting wide variety of elevations at north (Kruskop \& Shchinov, 2011; Abramov \&
Kruskop, 2012), but in Hon Ba Mountain it was reported to be separated from $M$. phanluongi exactly by elevation (Borisenko et al., 2009).

The new record on the southern slopes of Da Lat Plateau may provide new information about distribution and natural history of the latter species.

\section{Material and methods}

In April, 2013, complex research field trip to the Bao Lam District of Lam Dong Province was organized by the Vietnamese-Russian Tropical Center. Field works took place in Loc Bao Forestry, about $35 \mathrm{~km}$ north-west from the city of Bao Loc. During this study five individuals (four adult females and one male) of Myotis from the "siligorensis" species group were captured besides other bat species. Bats were captured using the Borisenko's "flap-trap". Voucher specimens then were fixed totally in $70 \%$ ethanol; skulls were extracted later during the laboratory processing of material.

To verify the provisional identification, two skulls from Loc Bao individuals (male and female) were measured and compared with 35 collection specimens of bats from the "siligorensis" species group, hosting in the collections of the Berlin Zoological Museum (Berlin, Germany), the Harrison Institute (Sevenoaks, UK), 


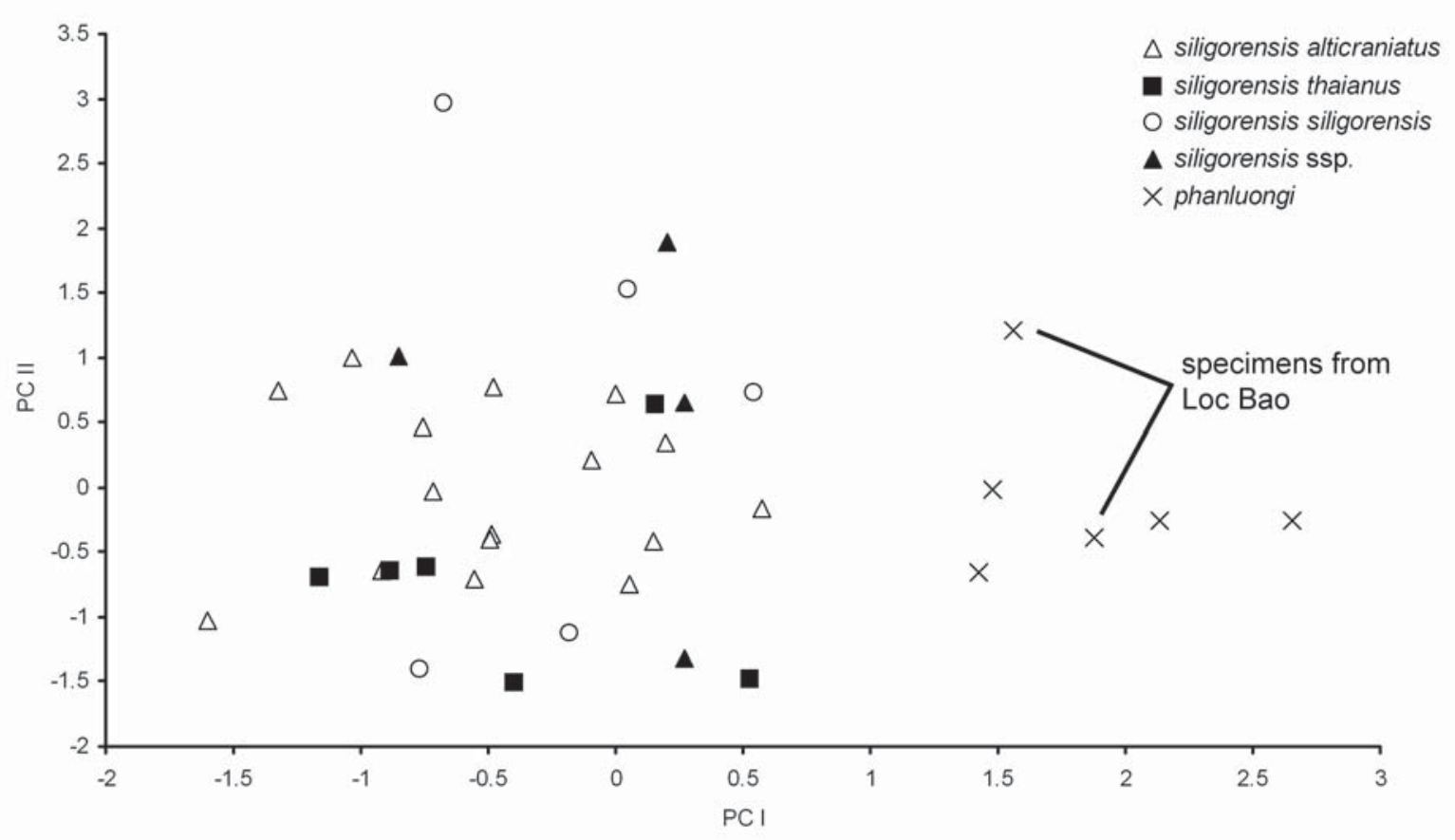

Figure. Bivariate scatterplot of the first two Principal Components calculated on the basis of fifteen cranial and dental measurements for 37 Myotis specimens. The first PC (eigenvalue $=8.72$, total variance ca. $58.1 \%$ ) is highly correlated with $\mathrm{CCL}, \mathrm{CBL}, \mathrm{LMD}$ and lengths of tooth rows, the second one (eigenvalue $=2.21$, total variance ca. $14.7 \%$ ) has high correlation with IOW.

the Museum of Natural History (London, UK), the Royal Ontario Museum (Toronto, Canada), the Senckenberg Natural History Museum (Frankfurt am Main, Germany) and the Zoological Museum of Moscow State University (Moscow, Russia). This comparative material includes four $M$. phanluongi, five $M$. siligorensis siligorensis from India and Myanmar, sixteen $M . s$. alticraniatus from different parts of Vietnam, six $M$. s. thaianus from Thailand, and four M. siligorensis of uncertain subspecies affiliation from Southern China. Fifteen measurements taken to the nearest $0.01 \mathrm{~mm}$ with a digital caliper in combination with a binocular microscope, were used in the final analysis, namely: condylobasal length (CBL), condylocanine length (CCL), width of the skull at the level of the auditory bullae (W), width of braincase (BCW), height of braincase posterior to the auditory bullae $(\mathrm{BCH})$, least interorbital width (IOW), C-M3 length (CM3), length of interval between cingulum of upper canine and large premolar ("pseudodiastema", PD), length of the upper canine crown at base $(\mathrm{C})$, molariform tooth row length (P4M3), crown measured width between outer margins of upper canines (CC), crown measured width between outer margins of M3 (M3M3), lower jaw length from alveolus of I1 to the articulated process (LMD), lower jaw height on the level of the tip of the coronoid process (HMD), crown length of maxillary tooth row (MCM3). Principal Component (PC) and Discriminant Function (DF) analyses were performed using STATISTICA 5.5 for Windows (StatSoft, Inc., 1999).

\section{Results and discussion}

Taking into account relatively large size of Loc Bao individuals (forearm 33.9-35.2 mm, body weight 3.2$4.3 \mathrm{~g}$ ) we supposed that these specimens should be $M$. phanluongi since corresponding average measurements for Vietnamese M. siligorensis are smaller (33.13 \pm 1.27 and 3.16 \pm 0.44 , respectively).

As follows from the results of PC analysis, Myotis phanluongi is clearly separated from $M$. siligorensis by the mean of first Principal Component (Figure). This Component is highly correlated with overall skull size and lengths of upper and lower tooth rows, reflecting more robust skull and dentition in $M$. phanluongi in comparison to $M$. siligorensis. DF analysis also support significant separation between $M$. phanluongi from three subspecies of $M$. siligorensis $(p<0.0001)$, showing squared Mahalanobis distances between groups definitely exceeding distances within groups. In both analyses Loc Bao specimens demonstrate clear affiliations with $M$. phanluongi, strongly supporting field identification. Noticeable, that meantime we did not found any significant difference between geographically distant forms of $M$. siligorensis by the same analysis.

Thus we possess a new site for $M$. phanluongi, situated on the opposite side of Da Lat Plateau in connection to the previous two records. The new record was made at approximately $900-1050 \mathrm{~m}$ above sea level which is the lowest elevation for this species and therefore extends known vertical distribution of $M$. 
phanluongi. All five animals were captured while foraging over the forest road surrounded by variably disturbed evergreen forest. Observed foraging behavior was similar to other "forest edge" Myotis like M. muricola: animals flew fast and maneuverable along the tree-less space at about three to seven meters above the ground. This demonstrates that foraging behavior of $M$. phanluongi can be flexible and not necessary should be connected with riverine habitats.

In Loc Bao individuals of $M$. phanluongi foraged in the same habitat and along with Glischropus bucephalus for which this record is the most high-elevated (at least in Vietnam). In the same place and habitats four other species were observed though not strictly contemporary to $M$. phanluongi: Rhinolophus pearsonii, $M$. muricola, Pipistrellus coromandra and Tylonycteris pachypus. On the whole local bat community demonstrates intermediate composition between that of lowlands or middle elevations (Glischropus, Tylonycteris, $M$. muricola) and Vietnamese highlands ( $P$. coromandra, M. phanluongi). Opposite to $M$. muricola, individuals of $M$. phanluongi are more cautious and after the first attempt to catch them kept some distance from the researcher. There flight maneuverability exceeds that of M. muricola. Observed echolocation calls were typical to Myotis steep FM with maximum energy at approximately $60 \mathrm{kHz}$. This differs significantly from very silent and more low frequency $(42-45 \mathrm{kHz})$ echolocation calls observed in previously known sites (Borisenko et al., 2009; Abramov et al., 2010). Such difference in the design of echolocation calls well correlate with vocalization variability observed by us in different populations of M. siligorensis alticraniatus (Kruskop, 2003; Abramov \& Kruskop, 2012).

ACKNOWLEDGEMENTS. I am sincerely grateful to the director of Tropical Center Southern Branch V.L. Trunov, A.B. Vassilyeva, E.A. Galoyan and all other colleagues who help me during the field studies. I am thankful to the general director of Tropical Center A.N. Kuznetsov and Nguyen Dang Hoi for the facilitating of the field survey. Laboratory processing of the material was held with the financial support from Russian Foundation for Basic Research (grant No.13-04-00439-a).

\section{References}

Abramov A.V. \& Kruskop S.V. 2012. The mammal fauna of Cat Ba Island, northern Vietnam // Russian Journal of Theriology. Vol.11. No.1. P.57-72.

Abramov A.V., Kruskop S.V. \& Schinov A.V. 2010. Small mammals of the Dalat Plateau, southern Vietnam // Russian Journal of Theriology. Vol.8 (for 2009). No.2. P.6173.

Borisenko A.V., Kruskop S.V. \& Ivanova N.V. 2009. A new mouse-eared bat (Mammalia: Chiroptera: Vespertilionidae) from Vietnam // Russian Journal of Theriology. Vol.7 (for 2008). No.2. P.57-69.

Kruskop S.V. 2003. [Records of bats in Ke Bang (Central Vietnam) with comments on their natural history] // Korzun L.P. \& Kalyakin M.V. (eds.) [Materials of Zoological and Botanical Studies in Ke Bang Area of the Phong Nha Nature Reserve (Quang Binh Province, Vietnam)]. Moskva-Khanoi: GEOS. P.102-127 [in Russian with English summary].

Kruskop S.V. 2013. Bats of Vietnam. Checklist and an Identification Manual. Second edition, revised and supplemented. Biodiversity of Vietnam Series. Moscow: KMK Scientific Press. 300 p.

Kruskop S.V. \& Shchinov A.V. 2011. New remarkable bat records in Hoang Lien Son mountain range, northern Vietnam // Russian Journal of Theriology. Vol.9. (for 2010). No.1. P.1-8.

Tiunov M.P., Kruskop S.V. \& Jiang Feng. 2011. A new mouse-eared bat (Mammalia: Chiroptera, Vespertilionidae) from South China // Acta Chiropterologica. Vol.13. No.2. P.271-278. 